\title{
All-optical demultiplexing using an electroabsorption modulator
}

\author{
Højfeldt, Sune; Bischoff, Svend; Mørk, Jesper
}

Published in:

Proceedings of Lasers and Electro-Optics

Link to article, DOI:

10.1109/CLEO.2000.907091

Publication date:

2000

Document Version

Publisher's PDF, also known as Version of record

Link back to DTU Orbit

Citation (APA):

Højfeldt, S., Bischoff, S., \& Mørk, J. (2000). All-optical demultiplexing using an electroabsorption modulator. In Proceedings of Lasers and Electro-Optics (pp. 342-343). IEEE. https://doi.org/10.1109/CLEO.2000.907091

\section{General rights}

Copyright and moral rights for the publications made accessible in the public portal are retained by the authors and/or other copyright owners and it is a condition of accessing publications that users recognise and abide by the legal requirements associated with these rights.

- Users may download and print one copy of any publication from the public portal for the purpose of private study or research.

- You may not further distribute the material or use it for any profit-making activity or commercial gain

- You may freely distribute the URL identifying the publication in the public portal

If you believe that this document breaches copyright please contact us providing details, and we will remove access to the work immediately and investigate your claim. 


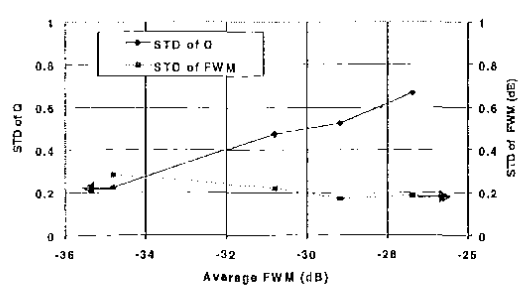

CWK69 Iig. 2. Measured standard deviations of $Q$ as a function of avcrage FWM crosstalk.

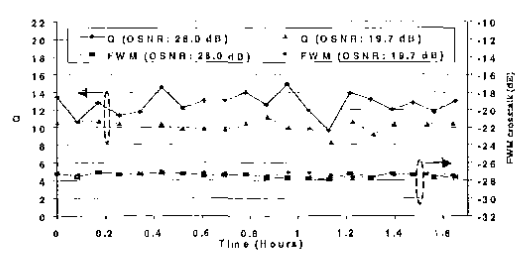

CWK69 Fig. 3. Measured Q values for different OSNR in 1.7 hours.

for case (b). Also no obvious correlation between the FWM crosstalk variations and $Q$ flucluations was observed. liks. 2 gives the stanclard deviations ( $\left.\left.S^{\prime} I^{\prime}\right]\right)$ ) of measured () as a function of the average FWM crosstalk. It shows that the magnitusles of fluctuations of $Q$ valucs increase as FWM crosstalk increases, while the standard deviation of l'WM crosstalk decreases slowly with the increase of the average FWM crosstalk. Therefore, the fluctuations of $Q$ values are not correlated to the variations of liWM crosstalk level.

To further cvaluate the $Q$ variations, we meisured $Q$ valttes for different OSNR. Fig. 3 shows measured Q values in about 1.7 hours for two OSNRs, $19.7 \mathrm{~dB}$ and $28.0 \mathrm{~dB}$. 'The average FWM crosstalk level was unchanged for these two cases. From Fig. 3, we observe that increasing amplified spontancous cmission (decreasing OSNR) reduces not only the magnitude of ( $)$, but also the fluctuation of $\mathrm{Q}$. 'This is contrary to the FWM effect which reduces the magnitude of $Q$, but increase its fluctuations, as shown in Fig. 2.

lirom our measurement results, we believe that the Q fluctuations were related to FWM, but not induced by the variations of rWM crosstalk level. The causes of the Q fluctuation can be tracked in two directions. lirst, part of fluctuations may simply come from the accuracy reduction of the Q measurement method due to the non-Gaussian statistics of FWM crosstalk, which increases the difficulty to get a good fitting curve from the measured points and induces large fluctuations among different measurements even though the system performance might be quite stable. This can be justified by the fact that decreasing OSNR reduces the $Q$ flucluations, as shown in rig. 3.

The second reason of the $Q$ variations goes to the real system performance fluctuations. Though the FWM crosstalk varies little, but its phase may vary due to the laser frequency shifts and the variations of fiber characteristics. Thus the FWM degradation on the channel signals may vary since the interference effect of FWM on the channel signal depends on the phase. We would expect the sime from polarization states, since the interference effect of FWM also clepends on the polarization states of the channcl signals and the liWM signals. However, we know that polarization variations should also induce fluctuations on FWM crosstalk. ${ }^{7}$ But, as shown in l'ig. 2 and lig. 3, no large fluctuations were observed on HWM crosstalk. 'l'herefore, there should be no large polarization effect on the variations of system perfomance. 'l'he phase fluctuation is the main factor for the system performance fluctuations. 'l'his can be partly justified by the fact that measured $Q$ values drifted from time to time and also the magnitudes of the drifts are highly related to the levels of average FWM crosstalk.

In summary, we have investigated IFM induced $Q$ fluctuations in W'DM systems. Otu mcasured results show that FWM can induce large variations on system Q-factor. 'The magnitudes of the fluctuation on () have little correlation to the mignitudes of fluctuations of IWM power, but strongly depend on the aver. age FWM crosstalk level. We belicve that these flucluations mainly result from FWM induced non-Caunsian chatacteristics of the noise in channel signals and also from the variations of the phase coherency between the IWM signals and the channel signals. 'Thus, these fluctua. tions mily have great impacts on the performance of forwarcl-error correction (Ific) that will be implemented widcly in next generation WI M systems.

J. S. Song, el al., "Lxperimental study of four-wave mixing in non-zero dispersion fiber," Proc, of LLOS'97, WA 2, pp. 224 225, Nov. 1997.

2. S. Song, et al., "I ligher-order four-wave mixing and its effects it WDM systems," submitted to C.T.EO2000, San Prancisco, ('A, May, 2000.

3. N.S. Hargano, et al., "320 ( $\mathrm{b} / \mathrm{s}$ WDM transmission $(64 \times 5(\mathrm{~b} b / \mathrm{s})$ over $7,200 \mathrm{~km}$ using large mode fiber spans and chirped return-to-zcro signals," OIC'98, PDI2, San Josc, Feb. 1998.

4. II. T'iga, et al. "The first demonst ration of four-channel simultaneous performance measurement of long distance WDM transmission systens," Proc. of ECOC'99, Vol. II, pp. 188-189, Nice, Irance, Scpt. 1999.

5. K. Inoue, H. T'oba, "Hilser four-wave mixing in multi-amplifier systems with nonuniform chromatic dispersion," J. of I ightwave 'Technology, 13 (1) 89-93 (Jan. 1995).

6. S. Song, et al., "Intensity dependent eflects on four-wave mixing in optical fiber," J. of I.ightwave 'l'cchnology, 17 (11) 22852290 (Nov. 1999).

7. S. Song, et al., "A novel nonlizuar method for measuring polarization mode dispersion using four-wave mixing," To be published in J. of Jightwave T'echnology, 17 (1.2) (1999).

8. N.S. Bargano, et al., "Margin measurements in optical amplifier systems," Il:LE Photonics lelts. 5 (3) 304-306 (1993).

\section{CWK70}

All-optical demultiplexing using an electroabsorption modulator

S. Høifeldt, S. Bischoff, J. Mørk, Res, Ctr. COM, Technical Univ. of Denmark, Bldg. 344, I)K-2800, Lyngby, I)enmark; E-mail: sh@com.dlu.dk

In the last decade, the electroabsorption modulator (L $\Lambda \mathrm{M}$ ) has found a wide range of applications. liunctionalities such as polse gencration and demultiplexing by electrical modulation ${ }^{1}$ have been demonstrated using an LAM. Recently, all-optical wavelength conversion, ${ }^{2,3}$ demultiplexing, ${ }^{4}$ and signal regeneralion, ${ }^{5}$ have also been experimentally demonstrated. In this paper, we investigate all-optical demultiplexing from 80 to 10 Grbit/s.

Our model for a reverse-biased guantumwoll absorber is a large-signal model developed for studying all-optical wavelength conversion and signal regeneration, "l'he absorption recovery of the device is governed by the sweepout of photogenerated carricrs. Based on the experimental results in ${ }^{4}$ we take the sweep-out time to be $8 \mathrm{ps}$

Figure 1 shows the demultiplexing contiguration. An incoming 80-Cibit/s-signal at 1510 $\mathrm{nm}$ and a $10-\mathrm{Gb} i \mathrm{i} / \mathrm{s}$ control signal at $1520 \mathrm{~nm}$ are launched into an l: $\triangle M$ (band-gap at 1550) $\mathrm{nm}$ ). Through cross-absorption saturation, the control signal gates the desired channel. 'I'o investigate the demultiplexing capability of the HAM, we propagale various $80-$ Gbit/s bitpatterns through the device together with a 10-Ghit/s control signal. lioth consist of 3 ps wide pulses. The incoming signal had an extinction ratio (ISR) of 10 dls (pealk-to-floor), introduced to simulate noise in the signal. The control signal had an $L R$ of $20 \mathrm{~dB}$.

Tigure 2 shows the eye-diagrams as funclion of device length. The figure shows that at $l=85$ $\mu, m$, the channcls to be rejected are still quite sirong. At $L=125 \mu \mathrm{m}$, the rejected channels arc suppressed $\sim 9 \mathrm{~dB}$. In the cye for the 125 $\mu \mathrm{m}$ long device, a gated space is responsible for one of the strong remaining pulses. Duc to the combince effects of absorption saturation, and the fitnite sweep-out time, a galed space can cxperience a smaller absorption than a gated mark. 'This is an intrinsic property of this type of demultiplexing scheme used at high bitrates (compared to the sweep-out time), and hence the maximum obtainalble level of rejection at the output is very similar to the input stream $E R$ (here: $10 \mathrm{~dB}$ ), but lower. For simple demultiplexing, the device is simple and useful, but cannot compete with e.g. the Mach\%chnder interferometer in drop-functionality because there is no signal improvement.

l'igure 3 shows the suppression of the rejected chanuels compared to the demultiplexed chanmel as funclion of device length for different control pulse powers. As expected, higher control pulse power gives better rejection of neighboring channels. l'or each power level, the level-of-rejection increases up to a certain device length, beyond which the output power just decreases, thereby identifying an optimum device length.

Using a conlrol signal with only a $10 \mathrm{~dB} E R$ instead of $20 \mathrm{~dB}$, a power of $21 \mathrm{dlBm}$ gave the same maximum $E R$ that was obtained with a 14 


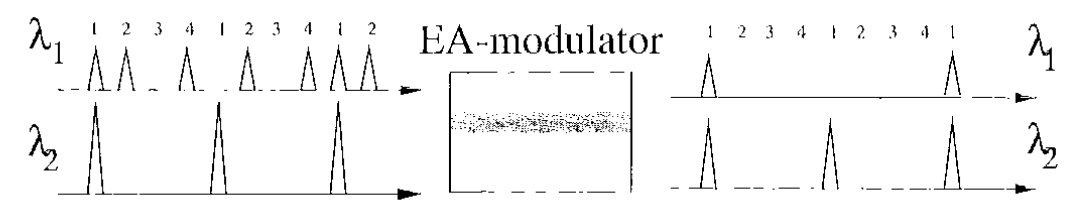

CWK70 Fig. 1. 'The demultiplexing configurationt: flere an incoming signal it $\lambda_{1}$ and a local control signal at $\lambda_{2}$ are launched into an electroabsorption modulator. $A$ the output, the signal aligned with the control signal is demultiplexed, the ofher three channels are rejected.

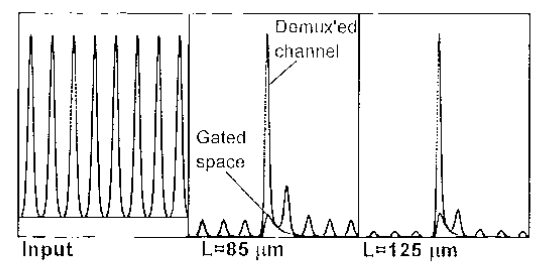

CWK70 Fig. 2. Fye diagrams of all 8 OT'I)M channels at the output as function of device length. At the input, all channels are equal, but into the device, other chamnels than the demultiplexed are rejected. The time window is 100 ps. 'The control pulse energy was $14 \mathrm{dBm}$, and the average C'l'LM pulse power was $7 \mathrm{dlBm}$.

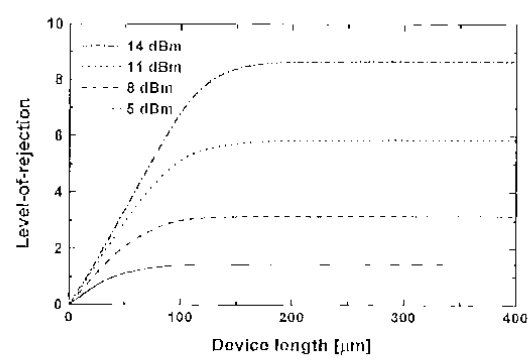

CWK70 Hig. 3. Level-of-rejection as function of length with average control pulse power as parameter. The level-of-rejection, determined by one of the rejected channels or by the gated space (whichever gives the worst eye), levels oul when the control pulses become tor weak to saturate the device, but the signal levels keep decreasing. Bit-patterns were chosen to obtain the greatest possille impairment.

dBm control signal with a $20 \mathrm{~dB} l l R$ (liig. 3), but for a longer device of $210 \mu \mathrm{m}$.

In summary, we have modeled all-optical demultiplexing using an clectroabsorption modulator, and shown critical dependence of the level-of-rejection on device length and control signal power. 'The device is very simple, and suitable for demultiplexing OT'OM signals.

1. A.D. 1:llis, J.K. Lucek, 1). Pitcher, D.G. Moodie, 1). Cotter, "Full $10 \times 10 \mathrm{Gibit/s}$ OTDM data generation and demultiplexing using electroabsorption modulators," lilectron. Lett., 34, (18) 1766-1.767 (1998).

2. N. Edagawa, M. Suzuki, S. Yamamoto, "Novel wavelength converter using an electroabsorption modulator: conversion experiments at up to $40 \mathrm{Gbit} / \mathrm{s}$," in 'Tech. 1)ig. OFC'97, 1997, vol. 6 of 1997 'lechnical Digest Series, pp. 77--78.

3. N. Edagawa, M. Suzuki, S. Yamamoto,
"Novel Wavelength Converter Using an Flectroabsorption Modulator," IFicl: Trats. Hlectron., E81-C; (8) 1251-1257 (1998).

4. II, Kurita, I. Ogura, II. Yoksyama, "Ultrafast All-Optical Signal Processing with Mode-Locked Semiconductor Lasers," Il:.. ICI Trans. Jilectron., li81-C, (2) 129-139 (1998).

5. H. Yokoyama, Y. Hashimoto, H. Kurita, "Noise reduction in optical pulses and biterror-rate improvement with a semiconductor-waveguide saturable $a b$ sorber," in Tech. Dig. CILUO'98, 1998, vol. 6 of 1998 'lechnical Digest Series, pp. $502-$ 5() 3$.

6. S. Ilojfelelt, S. Bischoff, J. Mork, "Alloptical wavelength conversion and signal regencration using an electroabsorption moclulator," in T'ech. Jig, LEOS'99, 1999.

\section{cWK71}

Long-haul soliton transmission in a

standard fiber at $1.3 \mu \mathrm{m}$ with distributed Raman amplification

A. Okhrimchuk, G. Onishchukov, I. Lederer, Inst fiir Angewante Physik, liviedrich-Schiller Univ. Jena, Max-Wien-Platz 1, D-07743 Jena, Germany; li-mail: okhrimeilap.uni-jena.de, photonics(miap.uni-jena.de.

'The desired increase of transmission calpacity demands to develop optical amplifiers for the expanded optical communication window 1.3-1.6 $\mu \mathrm{m}$. Rannan fiber amplifiers are among the most promising candidates to achieve this goal because of their flexibility regarding the operation wavelength, i.e., only a pump source with at appropriate wavelength is necessary. Broadband Raman amplificrs and Raman amplifiers as supplement to IIDHAs have attracted a considerable deal of interest in recent years, ${ }^{1,2}$ but beyond $1.5-1.6 \mu \mathrm{m}$ communication window the long-haul transmission with Raman amplification are not investigated yet. In this work we report on a transmission $\mathrm{ex}$ periment over $10,000 \mathrm{~km}$ with distributed Raman amplification in $1.3 \mu$ m region.

We have investigated $10 \mathrm{~Gb} / \mathrm{s}$ soliton propagation in the $1.3 \mu \mathrm{m}$ walvelenghth region using a re-circulating fiber loop set up. Distributed Raman amplification in a standard communication fiher was used to compensate for losses in the $24 \mathrm{~km}$ fiber and 5 dl3 losses in additional elements (3.1 $\mathrm{mm}$ optical bandpass filter, acousto-optical switch, $20 \%$ coupler, isolators). 'The counter-propagating pump scheme was chosen. 'The pump source was a $1.24 \mu$ m cascaded fiber Raman laser pumped by an $1.06 \mu \mathrm{m} \mathrm{Yb-doped} \mathrm{fiber} \mathrm{laser.} \mathrm{In} \mathrm{order} \mathrm{to}$
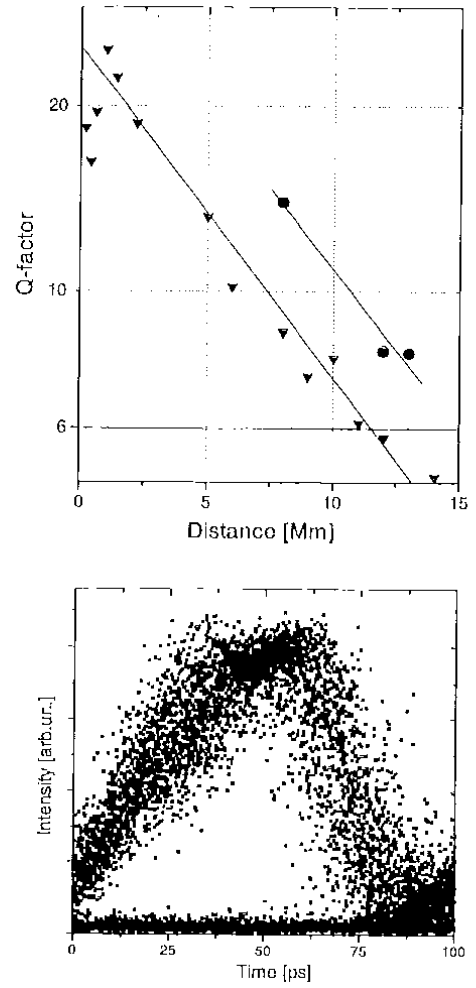

CWK71 Fig. 1. Q-factor dependence on distance for $1311 \mathrm{~mm}$ (triangles) and $1308.6 \mathrm{~nm}$ (circles). Typical cye diagram for $8000 \mathrm{~km}$ clistance

stabilize the Raman gain, the laser liode current in the $\mathrm{Yb}$ laser was controlled by the 1.24 $\mu m$ output of the Raman laser through clectro-optical fecdback. An intensity modulator governed by a random pulse generator was used to convert the optical pulses from an $\mathrm{cx}$ ternal cavity mode-locked semiconductor laser to the PRBS format.

We have obtained error free-propagation $(Q>6)$ up to $10000 \mathrm{~km}$ at $1307-1311 \mathrm{~mm}$ wavclengths in a fitser with zero dispersion at $1305.3 \mathrm{~mm}$. No stable propagation has been achieved at zero dispersion wavelength and in normal slispersion domain. For anomalous group velocity dispersion it has been found that the (2-factor strongly clepends on the pulse encrgy, and the optimum energy is found to be the fundatmental soliton energy. 'I'his optimum pulse energy is proportional to the fiber dispersion in the 1305.3-1306 nm range as for solitons with a fixed duration. 'the propagation near zero dispersion wavelength was poor because of low soliton energy and consequently low signal to noise ratio. 'The best results were obtained near $1308 \mathrm{~nm}$. Nontransform limited 20 ps input pulses are narrowed down to $5 \mathrm{ps}$ is a result of transformation into solitons during a few hundred $\mathrm{km}$. The dependence of the Q-factor on the dislance near the optimum wavelength and a typical cyc-diagram are shown in Fig. 1.

We have found that timing jitter and not the signal to noise ratio degradation is the main limiting factor for long distance transmission in such a system. 'The measured dependence of 